$a$
0
$\vdots$
0
0
0

July 1994

Distribution Category:

W. Chou

Feasibility Study of Aluminum Beam Tube for the Collider-An Option for No-Coating and No-Liner
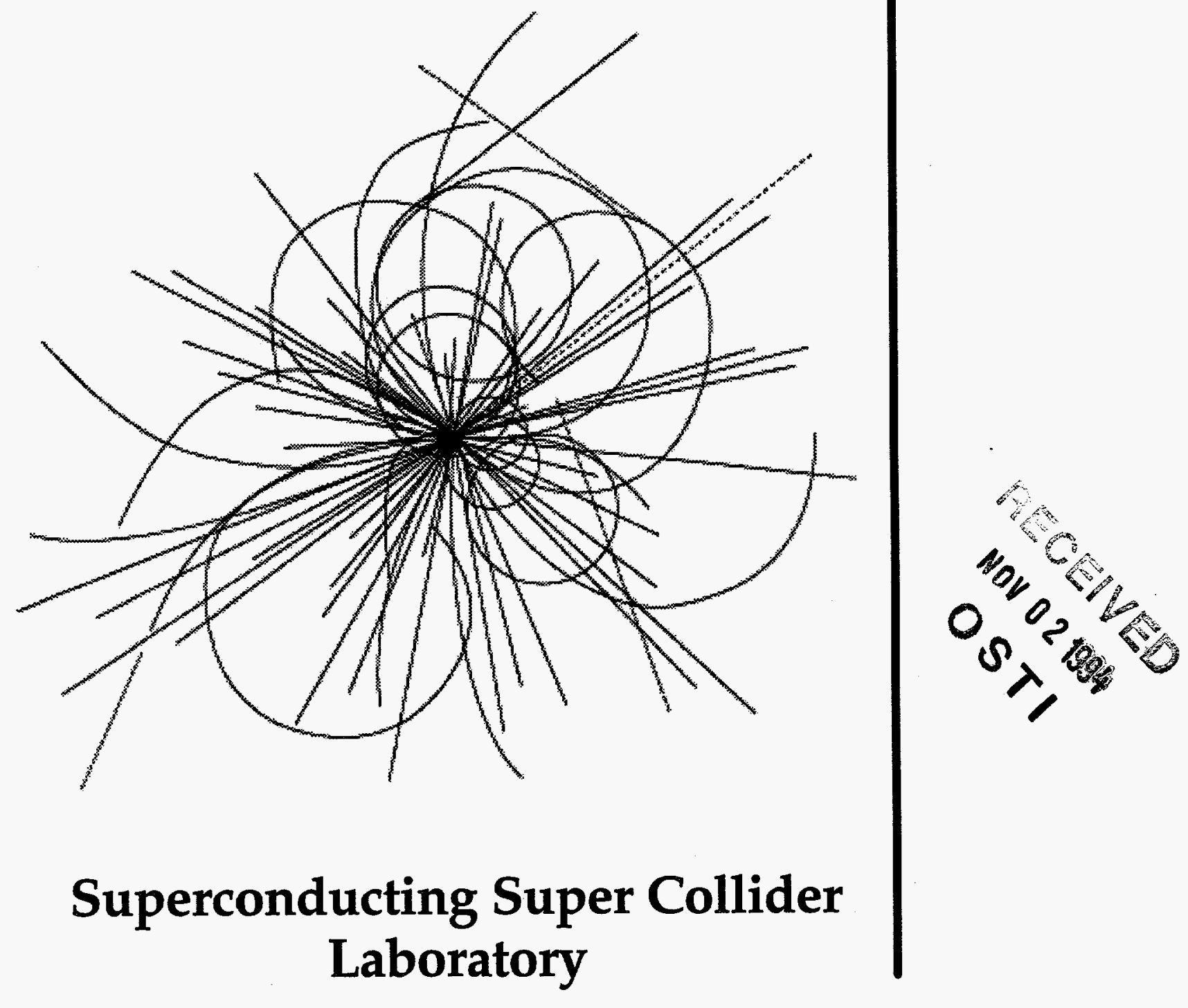


\section{Disclaimer Notice}

This report was prepared as an account of work sponsored by an agency of the United States Government. Neither the United States Government or any agency thereot, nor any of their employees, makes any warranty, express or implied, or assumes any legal liability or responsibility for the accuracy, completeness, or usefulness of any information, apparatus, product, or process disclosed, or represents that its use would not infringe privately owned rights. Felerence herein to any specific commercial product, process, or service by trade name, trademark, manufacturer, or otherwise, does not necessarily constitute or imply its endorsement, recommendation, or favoring by the United States Government or any agency thereof. The views and opinions of authors expressed herein do not necessarily state or reflect those of the United States Government or any agency thereof.

Superconducting Super Collider Laboratory is an equal opportunity employer. 


\section{DISCLAIMER}

Portions of this document may be illegible in electronic image products. Images are produced from the best available original document. 


\title{
Feasibility Study of Aluminum Beam Tube for the Collider- An Option for No-Coating and No-Liner
}

\author{
W. Chou \\ Superconducting Super Collider Laboratory* \\ 2550 Beckleymeade Avenue \\ Dallas, Texas 75237
}

July 1994

*Operated by the Universities Research Association, Inc., for the U.S. Department of Energy under Contract No. DE-AC35-89ER40486. 


\title{
Feasibility Study of Aluminum Beam Tube for the Collider- An Option for No-Coating and No-Liner
}

\author{
W. Chou
}

\begin{abstract}
This report proposes to use a single-layer beam tube made of high strength, high resistivity aluminum alloy (such as 7039-T61 or A7N01) to replace the double-layer copper coated stainless steel tube in the SSC Collider. The main reasons are: (1) a potential saving of about $\$ 23$ million which is basically the baseline cost of the copper coating and (2) the use of an extruded aluminum tube consisting of a beam chamber and a pumping chamber may solve the vacuum problem without any liner.
\end{abstract}




\subsection{INTRODUCTION}

The baseline design of the SSC Collider beam tube calls for a stainless steel (SST) pipe of about 2-mm thickness with a thin copper ( $\mathrm{Cu}$ ) layer (about 0.1-mm thick) coated on its inner surface. The purpose of the copper coating is to reduce the surface resistance, thus suppressing the possible beam instability caused by the resistive wall and reducing the beam-induced wall heating. But coating is expensive, estimated at about $\$ 2000$ for coating a 60 -foot tube. The total cost for the two rings would be about $\$ 20$ million. In addition, because of the vacuum problem, it recently became necessary to consider installing a liner inside the beam tube. This will certainly add cost on top of the $\$ 20$ million no matter how simple the liner design may be.

This paper suggests a drastic change in the choice of the beam tube, namely, a singlelayer aluminum ( $\mathrm{Al})$ alloy pipe without coating. The merits are as follows:

- There will be a potential saving of about $\$ 23$ million as shown in the following comparison:

Cu Coated SST Tube

$\begin{array}{ll}\text { A } 15-\mathrm{m} \text { 304LN tube } & \$ 930 \\ \text { Copper coating } & \$ 2000\end{array}$

Total

$\$ 2930$
Al Tube

A 15-m A7N01 tube, extruded Two Al-SST welding joints

$\$ 240$

Two Al-SST demountable joints $\$ 156$

Total

$\$ 596$

(Note: The costs of leak tests, inspections, storage and handling are not included.)

This gives a saving of $\$ 2334$ per tube, or $\$ 23$ million for a total of about 10000 tubes. (The need for Al-SST joints when aluminum tube is used will be discussed in Section 2.4.)

- If a 4-K liner becomes necessary because of the synchrotron radiation induced photodesorption problem, an extruded aluminum tube with a specially designed cross section (with antechambers or plate insertions) will more easily accommodate a distributed cryopump and, therefore, will eliminate the need for a separated liner addition to the tube.

- There is a concern about adhesion in the bi-layer Cu+SST tube over a 25-year lifetime. This will not be a problem for a single-layer aluminum tube.

Aluminum beam tubes have been used in many lepton storage rings, e.g., PEP (SLAC), LEP (CERN), TRISTAN (KEK), CESR (Cornell), NSLS (BNL), and ALS (LBL). In the early CDG days (around 1986), an aluminum tube for the SSC was ruled out mainly because of the concerns about eddy currents and mechanical stability during quench, and 
the technical difficulty of making leak-free joints between aluminum and stainless steel. This option has never been seriously reconsidered since the establishment of the SSC Laboratory in 1989. In this report, we will show that the recent industrial development of some high strength, high resistivity aluminum alloys (e.g., 7039-T61 or A7N01) can meet performance requirements in a quench, and that the Al-SST joint problem has several solutions that have been successfully tested and employed in a cryogenic environment at DESY, KEK and LANL.

In Section 2.0, we will visit a number of technical issues associated with the adoption of a single-layer aluminum beam tube in the Collider and show that this is a feasible solution. This is followed in Section 3.0 by a discussion of four possible ways of implementation of an aluminum beam tube. Section 4.0 suggests a two-phase experiment study of this proposal.

\subsection{TECHNICAL ISSUES CONCERNING THE USE OF ALUMINUM BEAM TUBE IN THE COLLIDER}

\subsection{Surface Resistance}

\subsubsection{Low Frequencies-Resistive Wall Instability Problem}

In order to control the beam instability, the requirement on the surface resistance of the beam tube is:

$$
\sigma_{e} \Delta \geq 2 \times 10^{5} \Omega^{-1}
$$

in which $\sigma_{e}$ is the electrical conductivity and $\Delta$ the thickness of the tube. (Note: This specification is for a beam tube ID of $33 \mathrm{~mm}$. If the tube ID is increased to $41 \mathrm{~mm}$, the value will be reduced to $1 \times 10^{5} \Omega^{-1}$.)

This expression is valid when the thickness $\Delta$ is smaller than the skin depth $\delta$. Otherwise $\Delta$ should be replaced by $\delta$. Table 1 compares a thin copper layer (the baseline) with an aluminum alloy (7039-T61) tube. The residual resistivity ratio (RRR) of copper is taken to be 30. The resistivity of 7039-T61 alloy is shown in Figure 1. It is seen that the product $\sigma_{e} \Delta$ of a $3-\mathrm{mm}$ thick aluminum tube is comparable to that of a $0.1-\mathrm{mm}$ thick copper layer.

Table 1. Comparison of Surface Resistance.

\begin{tabular}{|l|c|c|c|c|}
\hline \multicolumn{1}{|c|}{ Material } & $\begin{array}{c}\sigma_{e} \\
\left(\Omega^{-1} \mathrm{~mm}^{-1}\right)\end{array}$ & $\begin{array}{c}\delta^{\dagger} \\
(\mathrm{mm})\end{array}$ & $\begin{array}{c}\Delta \\
(\mathrm{mm})\end{array}$ & $\begin{array}{c}\sigma_{e} \Delta \\
\left(\Omega^{-1}\right)\end{array}$ \\
\hline Cu layer $(\mathrm{RRR}=30)$ & $1.8 \times 10^{9}$ & 0.6 & 0.1 & $1.8 \times 10^{5}$ \\
\hline Al 7039-T61 tube & $5.6 \times 10^{7}$ & 3.6 & 3 & $1.7 \times 10^{5}$ \\
\hline
\end{tabular}

† At $\omega=0.1 \omega_{0}$, where $\omega_{0}$ is the angular revolution frequency. 


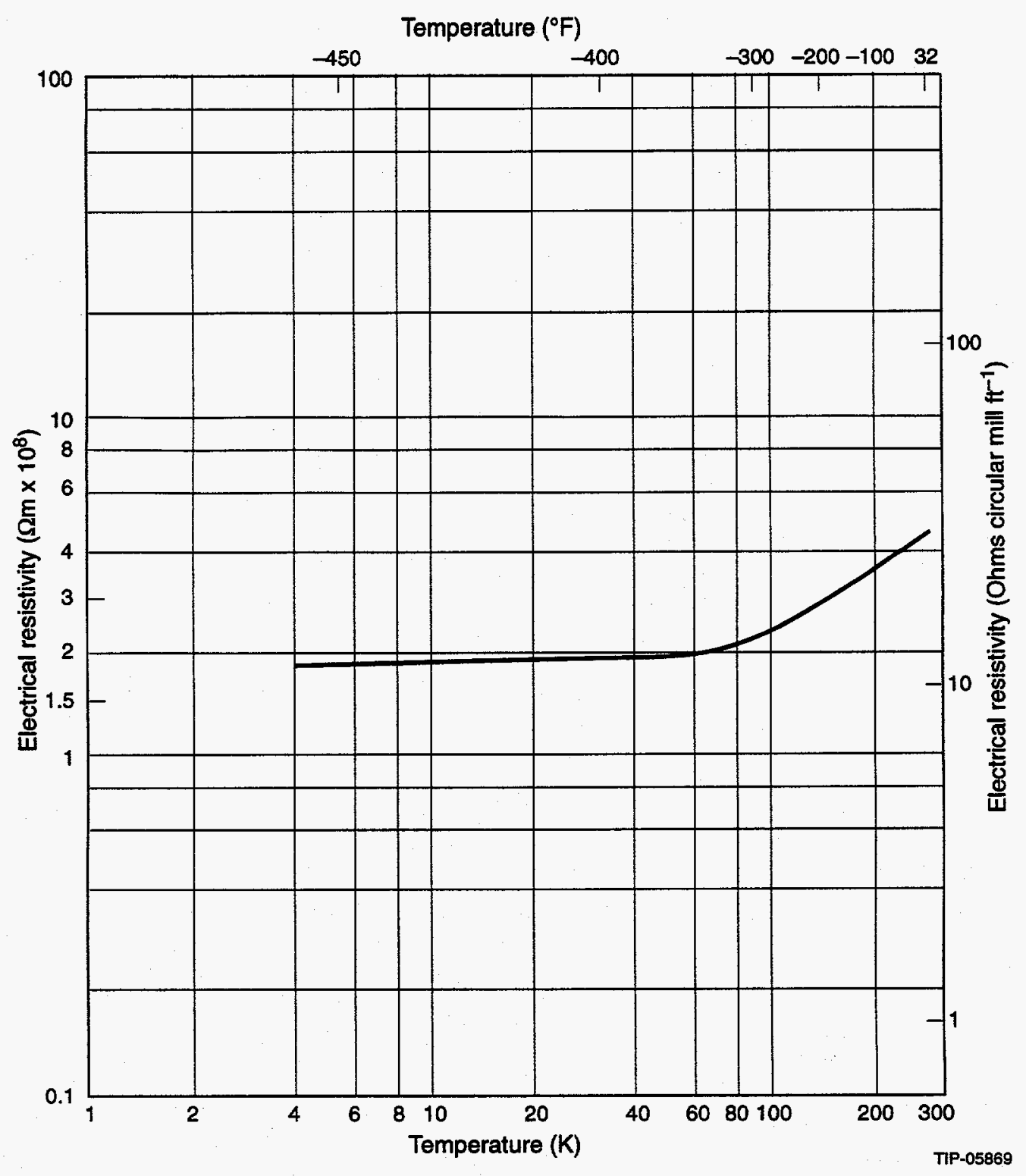

Figure 1. Electrical Resistivity Versus Temperature for Aluminum Alloy 7039-T61.

\subsubsection{High Frequencies-Rf Heating Problem}

In the 1986 blue CDR, it is said that the rf heating of an aluminum tube is several times greater than that of copper with $\mathrm{RRR}=30$. But in this comparison, the anomalous skin effect has been ignored.* The measurements on the if surface resistance of copper at $\mathrm{KEK},{ }^{1}$ University of Rochester ${ }^{2}$ and LANL show that, in the frequency range of $1 \mathrm{GHz}$

\footnotetext{
* When the frequency is high enough such that the mean free path of electrons becomes larger than the skin depth, the normal conduction theory based on electron collisions breaks down and the surface resistance becomes independent of the conductivity $\sigma_{e}$ of the material. This is called the anomalous skin effect.
} 
and above, the anomalous skin effect plays an important role. The surface resistance ratio $R_{s}(300 \mathrm{~K}) / R_{s}(4 \mathrm{~K})$ of copper at high frequencies is significantly lower than the dc value. The preliminary data measured by LANL using a copper-coated stainless steel tube (No. CU-SI-1-S) supplied by the SSCL is listed in Table $2 .^{3}$ It is evident that the rf heating needs to be recalculated using the measured data. Careful measurements are under way at LANL for both the copper-plated tube and the aluminum tube. Measurements in the presence of a strong magnetic field (up to 6.79 Tesla) are also being scheduled at the SSCL. A more realistic comparison is expected to be available soon.

Table 2. Surface Resistance Ratio of a Copper Plated Tube.

\begin{tabular}{|l|c|}
\hline Frequency & Ratio $R_{s}(300 \mathrm{~K}) / R_{s}(4 \mathrm{~K})$ \\
\hline $\mathrm{dc}$ & 107 \\
\hline $0.959 \mathrm{GHz}$ & 4 \\
\hline $1.865 \mathrm{GHz}$ & 3.2 \\
\hline $7 \mathrm{GHz}$ & 3.7 \\
\hline
\end{tabular}

\subsection{Quench Problem}

\subsubsection{Eddy Current}

The eddy current during quench is proportional to the product $\sigma_{e} \Delta$ :

$$
I=2 \dot{B} b^{2} \cdot \sigma_{e} \Delta
$$

in which $\dot{B}$ is the rate of decrease of the magnetic field $B$, and $b$ is the beam tube radius. It is seen from Table 1 that the eddy current should be about the same for a $0.1-\mathrm{mm}$ thick copper layer and for a 3-mm thick aluminum tube.

\subsubsection{Quench Pressure and Tube Thickness Requirement}

During quench, there is an isotropic pressure $P_{\mathrm{He}}$ (in the radial direction pointed inward) on the beam tube from the vaporized helium. The Magnet System Division (MSD) specification of this pressure is:

$$
P_{\mathrm{He}}=488 \mathrm{psi} \text {. }
$$

In addition, there is a non-uniform pressure (in the horizontal direction pointed outward) due to the Lorentz force. The Lorentz pressure has a $\cos \theta$ distribution and peaks at the equator with the maximum value

$$
P_{\max }=B \dot{B} b \cdot \sigma_{e} \Delta
$$


The test data shows that $B \dot{B}$ has its maximum value of about $150 \mathrm{Tesla}^{2} / \mathrm{s}$ at 0.2 second after the quench occurred. This gives a $P_{\max }$ of $76 \mathrm{psi}$ for a tube ID of $41 \mathrm{~mm}$. As a conservative measure, we take

$$
P_{\max }=100 \mathrm{psi} \text {. }
$$

According to the rule set by the American Society of Mechanical Engineers (ASME), the maximum stress for membrane loading should not exceed the following allowable value:

$$
\sigma_{\text {allow }}=1.5 \times \min \left\{0.25 \sigma_{\mathrm{t}}^{\mathrm{u}}, 0.67 \sigma_{\mathrm{t}}^{\mathrm{y}}\right\}
$$

in which $\sigma_{t}^{\mathrm{u}}$ is the ultimate tensile strength of the tube material, and $\sigma_{\mathrm{t}}^{\mathrm{y}}$ is the yield tensile strength. The tensile strength of the aluminum alloy 7039-T61 is high as shown in Figure 2. At $4 \mathrm{~K}$, one has

$$
\begin{aligned}
& \sigma_{\mathrm{t}}^{\mathrm{u}}=98 \mathrm{ksi}, \\
& \sigma_{\mathrm{t}}^{\mathrm{y}}=77 \mathrm{ksi} .
\end{aligned}
$$

Therefore, the allowable strength is:

$$
\sigma_{\text {allow }}=36.75 \mathrm{ksi} \text {. }
$$

The following equation gives a quick estimate for the required tube thickness $\Delta:^{4}$

$$
P_{\mathrm{He}} \frac{R}{\Delta}+\frac{3}{2} P_{\max } \frac{R^{2}}{\Delta^{2}}\left(\frac{P_{\mathrm{c}}}{P_{\mathrm{c}}-P_{\mathrm{He}}}\right)=\sigma_{\text {allow }}
$$

in which $R$ is the outer radius of the tube $(22.5 \mathrm{~mm})$, and $P_{\mathrm{c}}$ is the critical buckling pressure. The latter is computed by:

$$
P_{\mathrm{c}}=\frac{Y}{4\left(1-\nu^{2}\right)}\left(\frac{\Delta}{\bar{R}}\right)^{3}
$$

in which $Y$ is the Young's modulus $\left(10^{7} \mathrm{psi}\right.$ for aluminum alloys), $\nu$ the Poisson ratio (0.33), and $\bar{R}$ the average tube radius. By solving Eqs. (5) and (6) simultaneously, we get $P_{c}=$ $1.7 \mathrm{ksi}$ and the required aluminum alloy beam tube thickness:

$$
\Delta=1.9 \mathrm{~mm} \text {. }
$$

(As a comparison, the required thickness of a stainless steel tube is $1.4 \mathrm{~mm}$.) A more careful and conservative method-the stress ratio method-gives a larger required thickness of the beam tube, which will be discussed in Section 2.2.4. 


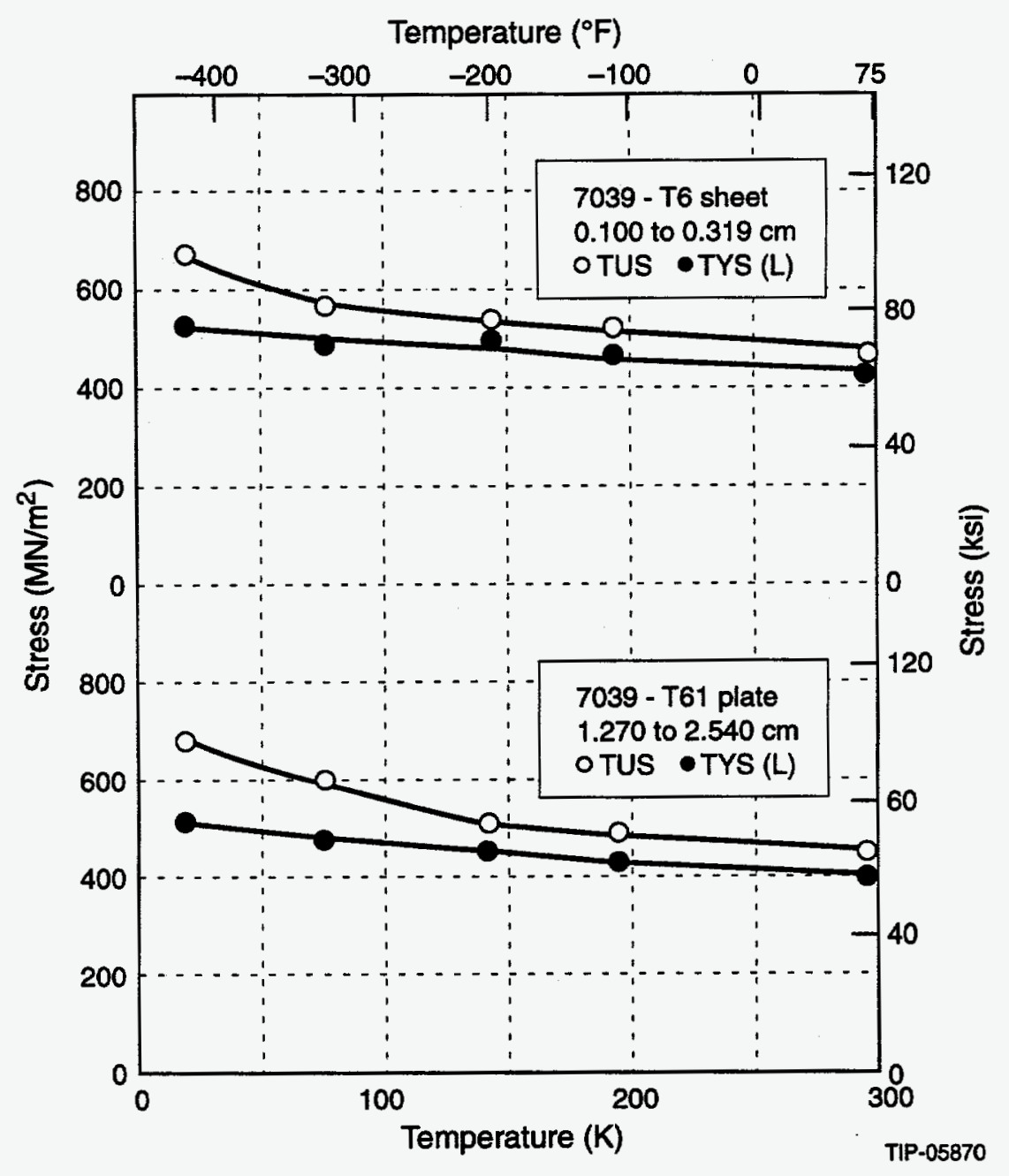

Figure 2. Effect of Temperature on the Strength of 7039 Aluminum Alloy.

\subsubsection{Stress and Elastic Deflection}

During quench, the radial deflection $\delta \ell$ of the tube must be small $(<1 \mathrm{~mm})$ so that no coil movement can occur. (This small amount of tube movement will be absorbed by the tube supports made of Kapton.)

In the absence of helium pressure, the maximum stress $\sigma_{\max }$ and the maximum deflection $\delta \ell_{\max }$ of a tube due to the Lorentz pressure have been worked out: ${ }^{5}$

$$
\begin{aligned}
\sigma_{\max } & =P_{\max } \times 1.5\left(\frac{b}{\Delta}\right)^{2}, \\
\delta \ell_{\max } & =\frac{\sigma_{\max } b^{2}}{Y \Delta} .
\end{aligned}
$$


By using the parameters in the previous section, for a 3-mm thick aluminum tube we get $\sigma_{\max }=7 \mathrm{ksi}$ and $\delta \ell_{\max }=0.1 \mathrm{~mm}$. Meanwhile, the 3-D computer simulation gives $\sigma_{\max }=7.3 \mathrm{ksi}$ and $\delta \ell_{\max }=0.07 \mathrm{~mm} .{ }^{6}$ Both are in agreement.

The real situation is more complicated. One has to take three effects into account: thermal contraction during the cooldown from room temperature to $4.2 \mathrm{~K}$, the vaporized helium pressure and the Lorentz pressure. A stress analysis using the 3-D code ANSYS has been performed for a $3-\mathrm{mm}$ thick aluminum tube. ${ }^{7}$ It is shown in Figure 3 and gives the following results:

$$
\begin{aligned}
\sigma_{\max } & =12.3 \mathrm{ksi}, \\
\delta \ell_{\max } & =0.029 \mathrm{~mm} .
\end{aligned}
$$

These numbers are well within the tolerable limits. The corresponding data for a coppercoated stainless steel tube are $\sigma_{\max }=25 \mathrm{ksi}, \delta \ell_{\max }=0.023 \mathrm{~mm}$.

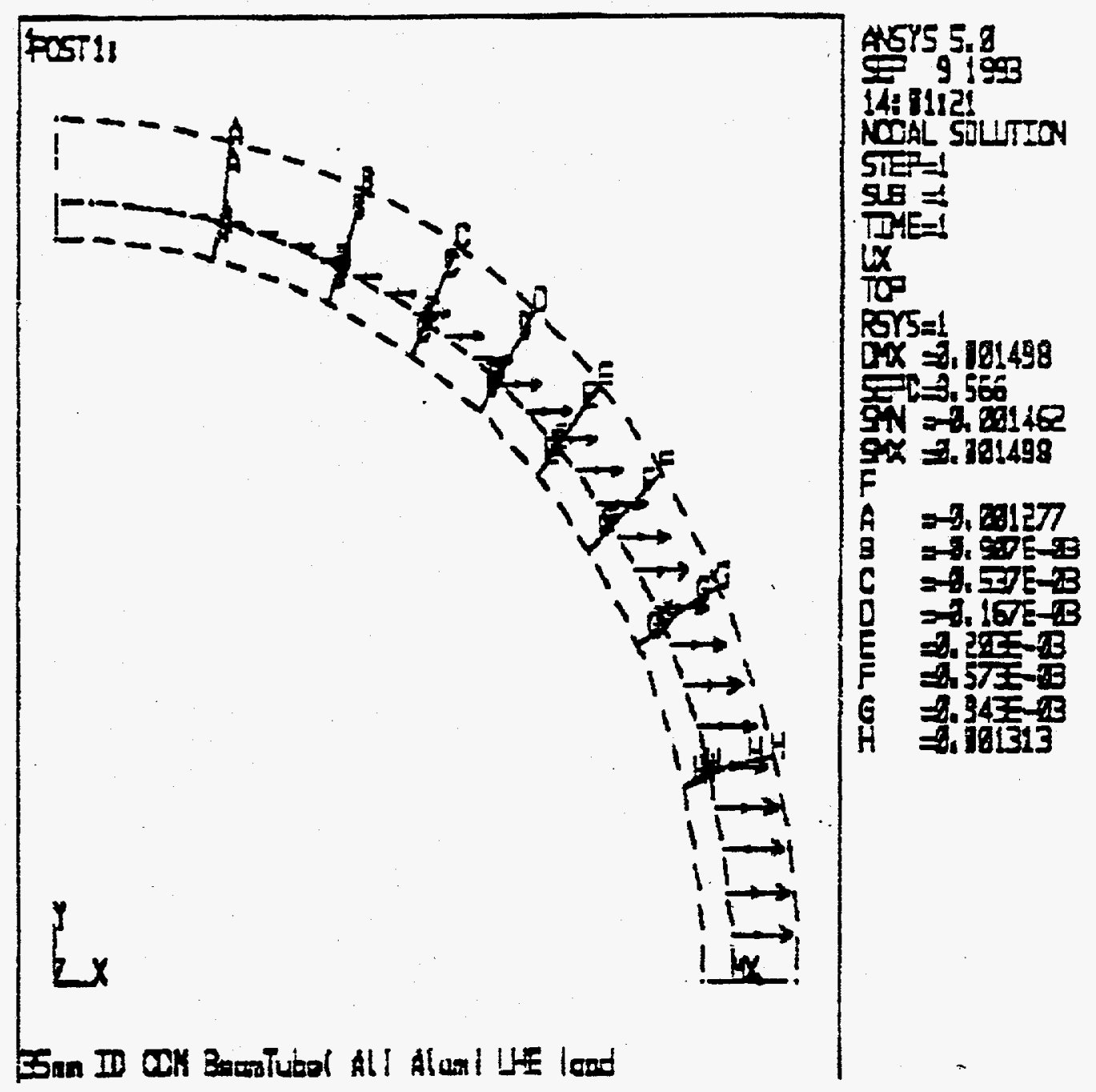

Figure 3. Stress and Strain Analysis for a 3-mm Thick Aluminum Tube Using ANSYS. 


\subsubsection{The Stress Ratio Method}

A more conservative and widely adopted method in mechanical engineering for estimating the required tube thickness is the stress ratio method. It states that the sum of the two ratios, $\sigma_{\max } / \sigma_{\text {allow }}$ and $P_{\mathrm{He}} / P_{\mathrm{c} \text { allow }}$, must be less than 1 . Using the results in the previous sections, we have for a $\Delta=3-\mathrm{mm}$ aluminum tube:

$$
\begin{aligned}
\sigma_{\max } & =12.3 \mathrm{ksi} \\
\sigma_{\text {allow }} & =36.75 \mathrm{ksi} \\
P_{\mathrm{He}} & =0.488 \mathrm{ksi} .
\end{aligned}
$$

From Eq. (6), for $\Delta=3 \mathrm{~mm}$ we get the critical buckling pressure:

$$
P_{\mathrm{c}}=8.2 \mathrm{ksi}
$$

According to ASME Sec. VIII, Div. 2, the allowable buckling pressure is:

$$
P_{\text {c allow }}=\frac{P_{c}}{4}=2.05 \mathrm{ksi} \text {. }
$$

Thus, the stress ratio is:

$$
\frac{\sigma_{\mathrm{max}}}{\sigma_{\text {allow }}}+\frac{P_{\mathrm{He}}}{P_{\mathrm{c} \text { allow }}}=\frac{12.3}{36.75}+\frac{0.488}{2.05}=0.33+0.24=0.56 .
$$

This ratio is less than 1 . Therefore, a $3-\mathrm{mm}$ thick aluminum tube should be satisfactory during quench.

The same analysis has been carried out for other values of thickness. The results are:

$$
\begin{array}{ll}
\text { stress ratio }=0.89, & \text { for } \Delta=2.5 \mathrm{~mm}, \\
\text { stress ratio }=1.52, & \text { for } \Delta=2.0 \mathrm{~mm} .
\end{array}
$$

In other words, the minimum thickness of an aluminum tube is about $2.5 \mathrm{~mm}$ by means of the stress ratio method.

\subsubsection{Quench Test}

A more convincing evidence of the quench survivability of an aluminum tube comes from a preliminary quench test. ${ }^{8}$ The test set-up is shown in Figure 4 . The sample is an A7N01 aluminum alloy pipe (1.7-mm thick), which is co-extruded with an A1100 pure aluminum pipe (0.2-mm thick). The pipe is about $2-\mathrm{m}$ long. The eddy current and Lorentz pressure of this clad pipe in a quench are comparable to what is calculated above. The test results showed that the elastic deformation was $<0.1 \mathrm{~mm}$, which agreed with our estimation. The plastic deformation was $<0.01 \mathrm{~mm}$. 


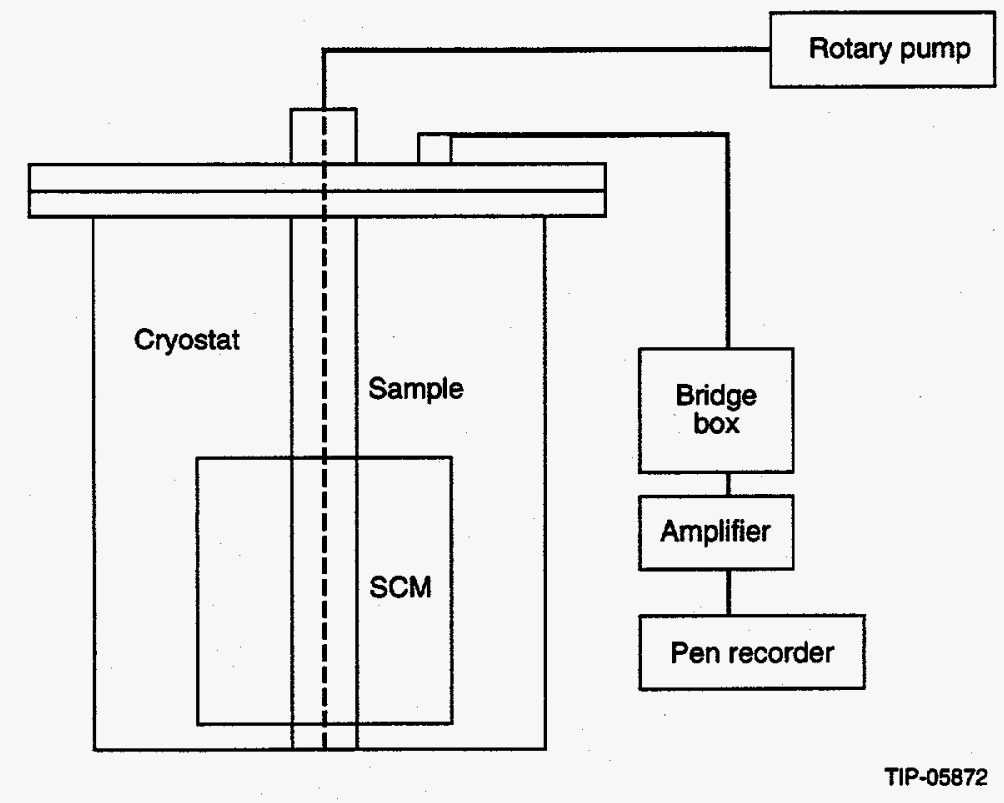

Figure 4. Quench Test Set-up. The sample is an aluminum alloy clad tube.

\subsection{Outgassing Problem}

\subsubsection{Photon Induced Gas Desorption}

The main concern of the vacuum problem in the Collider is the dynamic outgassing due to the synchrotron radiation from the $20-\mathrm{TeV}$ protons. The vacuum $\mathrm{R} \& \mathrm{D}$ program at the SSCL is seeking some surface material which has low photodesorption coefficient $\eta$ and low hydrogen inventory. The previous measurement at NSLS by H. Halama et al. showed that the initial $\eta$ of aluminum is higher than that of copper and stainless steel. But the rate of decrease is also greater, as shown in Figure 5. As observed by A. Mathewson at CERN, "The impression is that, at sufficiently high photon dose, the desorption coefficient for all three metals (i.e., $\mathrm{Al}, \mathrm{Cu}$ and SST) will tend to similar low values."

However, it should be pointed out that the 7000 series aluminum alloy contains a high percentage of zinc (4-5\%). Zinc is known for its high vapor pressure and is not a favorable material for a vacuum chamber. Whether this could be a problem is not clear to us. A thermal outgassing measurement using $\mathrm{A} 7 \mathrm{~N} 01$ has been carried out by $\mathrm{H}$. Ishimaru and his colleagues. The results show no difference between A7N01 and 6061, which is encouraging. New photodesorption measurements using aluminum tubes are being planned at BNL and KEK. They will provide additional information on this subject. 


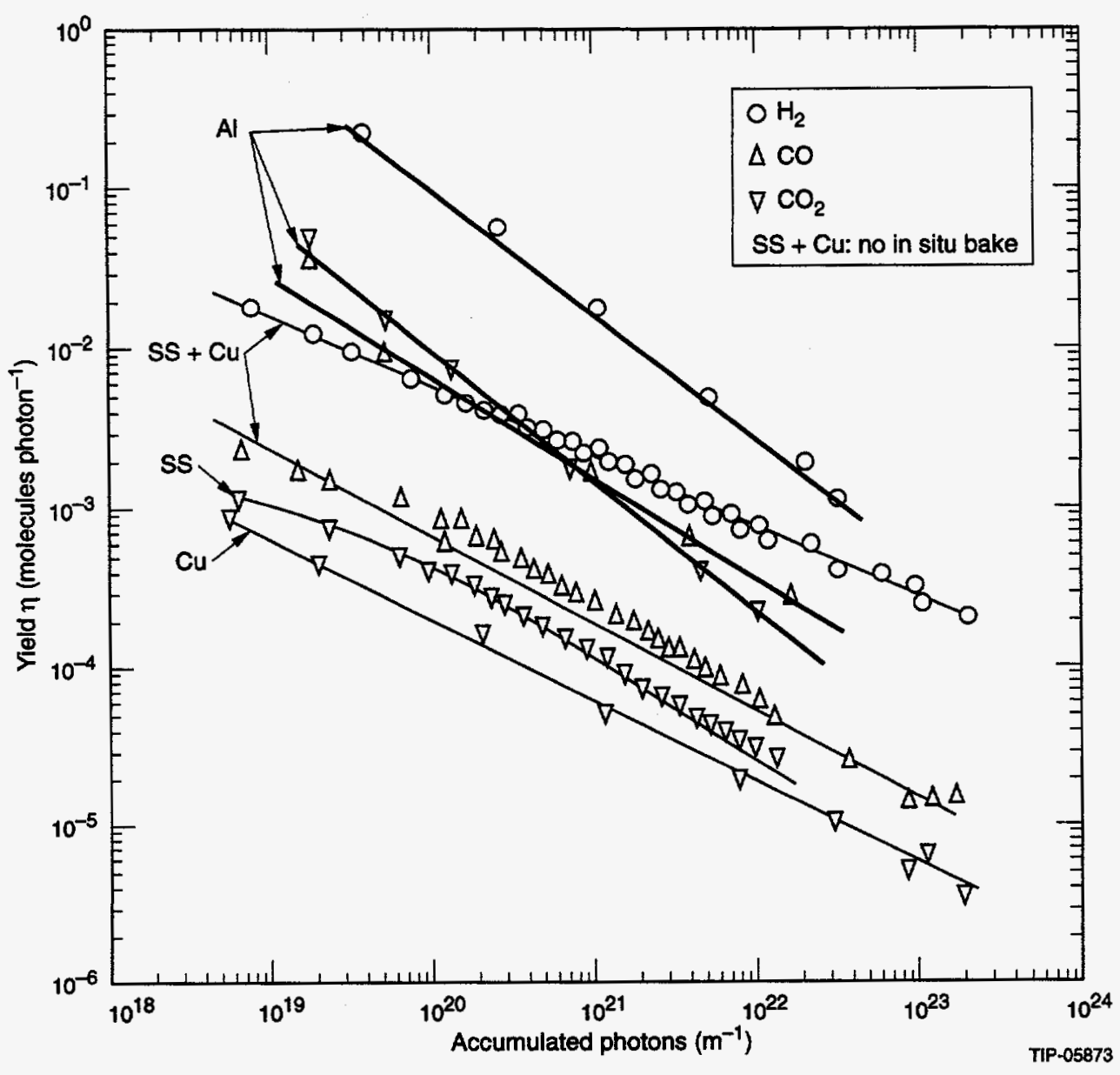

Figure 5. Photodesorption Coefficient $\eta$ of Several Metals as a Function of Photon Dose.

\subsubsection{Ion Induced Gas Desorption}

Another dynamic outgassing mechanism is provided by ionized molecules of the residual gas accelerated by the potential field of the proton beam, which is about $400 \mathrm{~V}$ for a beam current of $0.07 \mathrm{~A}$ in the Collider. The ions can desorb gas molecules from the accumulated layer on the tube surface. This effect is usually described by the quantity $\eta_{i} I$, the product of the ion desorption coefficient $\eta_{i}$ and the beam current $I$. Thanks to the low beam current in the SSC Collider, calculation shows that this effect is small no matter what material ( $\mathrm{Al}, \mathrm{Cu}$ or SST) is used for the beam tube.

\subsubsection{Electron Multipactoring}

The third dynamic outgassing mechanism is electron multipactoring. This is a resonance phenomenon which occurs when certain conditions are fulfilled in the proton bunch 
spacing and secondary electron emission. Because aluminum has a high secondary electron emission coefficient, this may become a problem as has been observed in the ISR. However, the calculations using Gröbner's model show that multipactoring would not occur when aluminum tube is used in the Collider due to the low beam current and short bunch length in the SSC. ${ }^{10}$ On the other hand, some precautionary measure (e.g., a titanium-nitride coating) may be considered to avoid this effect.

\subsection{Al-SST Joint Problem}

In room temperature accelerators, the joint between aluminum and stainless steel has found satisfactory solutions. For example, SLAC pioneered ways of joining Al tubes to SST flanges using explosive bonded material from DuPont. In the LEP, the aluminum tubes are interconnected by bolted flanges of dissimilar metals (aluminum and stainless steel) with aluminum gaskets and stainless steel bellows. (Note that the tubes were baked out at $150^{\circ} \mathrm{C}$ for 24 hours after installation.) Another machine, TRISTAN, uses an all-aluminum alloy vacuum system (the beam tube, flanges, valves, bellows, etc.).

However, the Al-SST joint in a cryogenic storage ring presents a technical challenge. Here the concern is the possible leak of helium at the joint near the end of the coldmass. There are several solutions that have been tested and used in a helium environment.

- The demountable joint: ${ }^{11}$

It uses bolted aluminum and stainless steel flanges manufactured by Hakudo/SMC. It is employed in the superconducting RFQ of the GTA project at LANL. In the tests, the pipe contains helium gas at 450 psi. After 100 thermal cycles between room temperature and $22 \mathrm{~K}$, there was no detectable helium leak from the joint. This type of joint is commercially available. The market price for $2 \frac{1}{4}^{\prime \prime}$ flanges is: $\$ 38$ per Al flange, $\$ 30$ per SST flange, $\$ 9.44$ per Al gasket. That is a total of about $\$ 78$ for each joint.

- The explosion bonded Al-SST transition piece:

This has been used in cryogenic and vacuum environments at KEK for years and proved reliable and leak-free. The cost also looks reasonable. One can purchase a $50 \mathrm{~cm} \times 50 \mathrm{~cm}$ transition plate (which can be machined to make dozens of joints) for about $\$ 1000$ from the manufacturer (such as Asahi Chemical).

- The friction welding method:

A more interesting demonstration of the reliability of the Al-SST joint at cryotemperatures is provided at DESY. In the dipoles of the HERA proton ring, the helium cooling tube of the $40-\mathrm{K}$ shield is made of aluminum. It is connected to the stainless steel flanges and bellows by friction welding as shown in Figure 6 . In 
these joints, the helium pressure is 300 psi. During the past three years of HERA operation, no helium leak from these welds has been found. ${ }^{12}$

Although the working temperature of the HERA cooling tube is $40 \mathrm{~K}$, similar performance is expected at $4 \mathrm{~K}$. This is because the thermal contraction of aluminum alloy becomes very small under $40 \mathrm{~K}$ as shown in Figure 7 .

These joints are manufactured by a French company, Thevenet Clerjounie. The price is $\$ 132$ apiece. There will be a $20-25 \%$ discount for a mass order.

D. Clark has proposed a design for the Al-SST joints near the end of the coldmass that is illustrated in Figure 8. It uses one transition piece (friction welded or explosion bonded) and one demountable joint at each end.

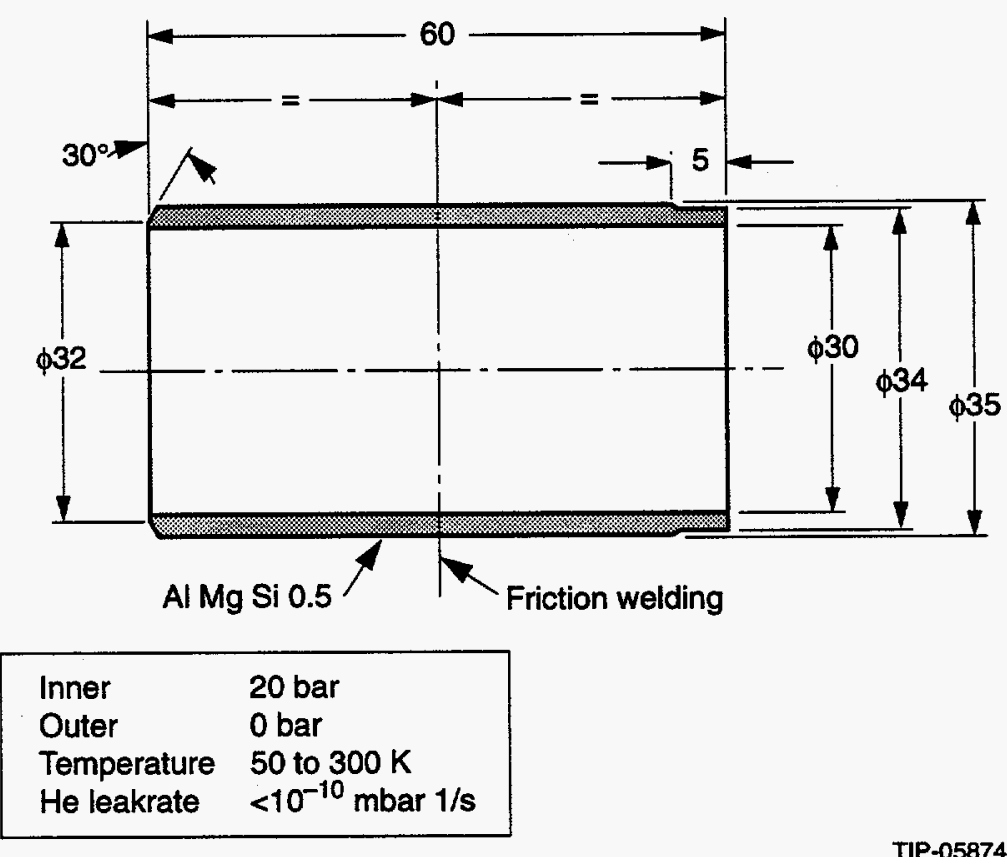

Figure 6. Al/SST Joint Used in the HERA Dipole. 


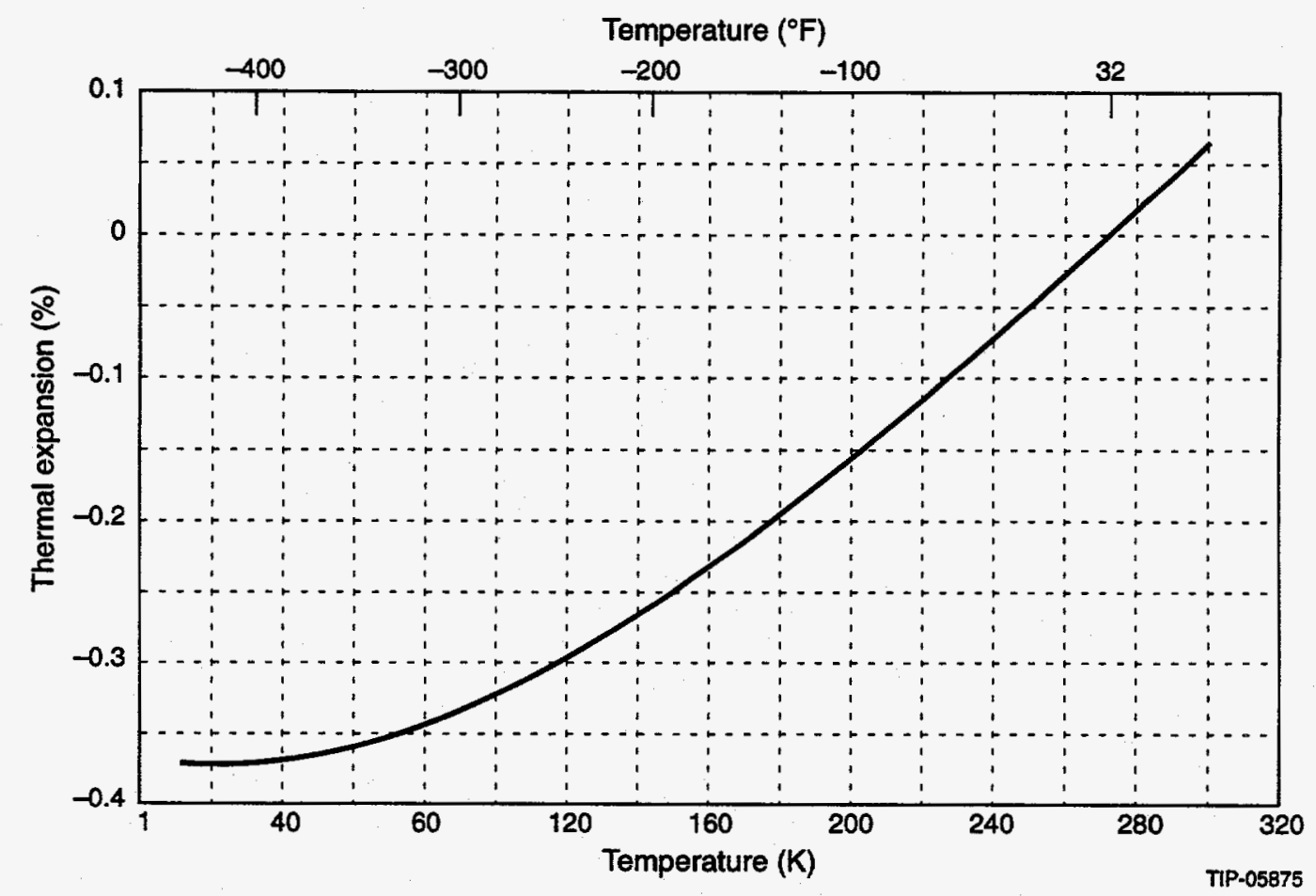

Figure 7. Thermal Expansion Versus Temperature for Aluminum Alloy 7039-T61.

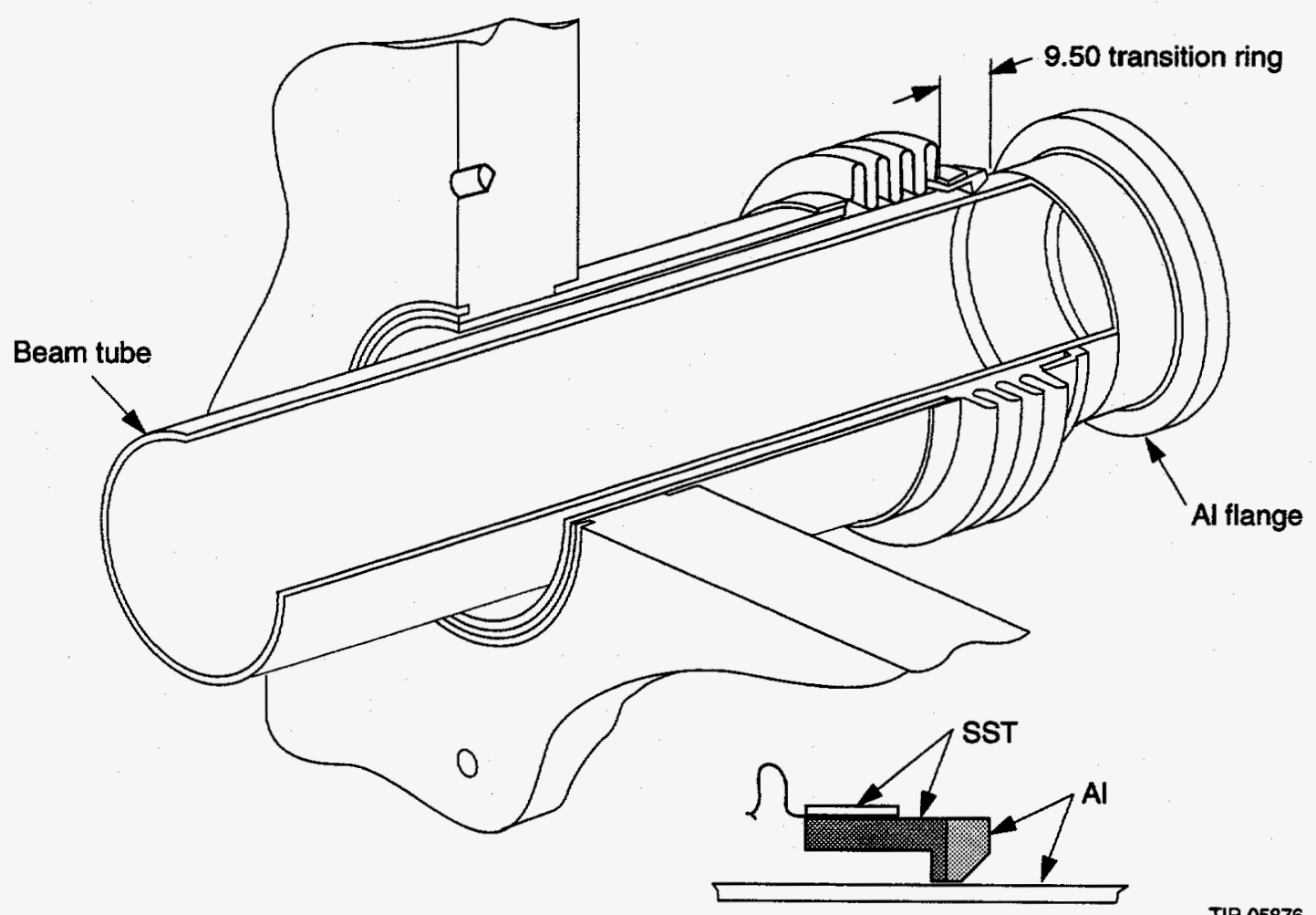

Figure 8. A Proposed Design for the Al-SST Joints at the End of the Coldmass for the Collider Dipole. 


\subsection{Other Issues}

\subsubsection{Beam Position Monitor (BPM)}

Each BPM has four signal leads that are connected to the four electrodes inside the beam tube. When an aluminum tube is used, one needs a ceramic-to-aluminum seal. This technology has been developed at KEK and tested at LHe temperature.

\subsubsection{Characteristics of Aluminum Alloy}

These include the elongation, weldability, machinability, resistance to corrosion, etc., of the alloy 7039-T61 and A7N01. They can be obtained either from the handbook Aluminum Standards and Data (published yearly by The Aluminum Association) or directly from manufacturers.

\subsubsection{Impact on Project Schedule}

One may be concerned about whether it is too late now to make such a change in the beam tube choice. This issue certainly needs to be studied carefully. From what we have learned from MSD, General Dynamics is presently considering a subcontract with Silvex for purchasing a small number (in the order of 100) of copper-coated stainless steel tubes. Therefore, there should be plenty of time for studying the aluminum alternative before any mass production is begun.

\subsection{IMPLEMENTATION OF ALUMINUM BEAM TUBE IN THE COLLIDER}

There are four different ways to employ the aluminum beam tube in the Collider.

\subsection{A Circular Beam Chamber}

This is simply to replace the double-layer copper-coated stainless steel tube by a singlelayer aluminum alloy tube as shown in Figure 9 . The OD is $45 \mathrm{~mm}$, ID $39 \mathrm{~mm}$, wall thickness $3 \mathrm{~mm}$. The loss of $2 \mathrm{~mm}$ in the annular space due to a thicker wall (compared with the 2-mm thick stainless steel tube in the baseline) should be tolerable.

This implementation will eliminate the $\$ 20$ million coating cost but it will also inherit the vacuum problem in the baseline design. 


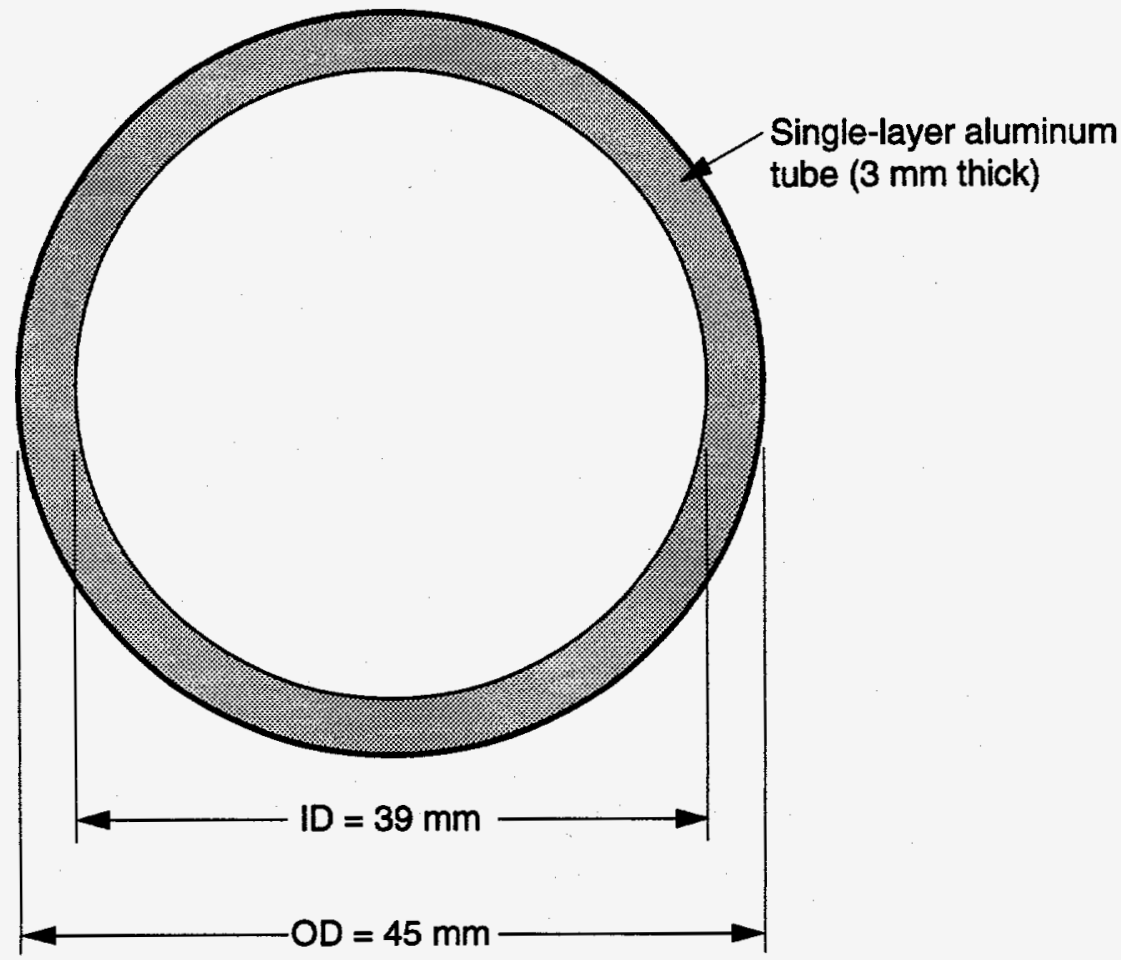

TIP-05877

Figure 9. A Circular Aluminum Alloy Beam Tube for the Collider.

\subsection{A Beam Chamber with Antechambers}

Because aluminum is relatively easy to extrude, one may design a complex cross section for the beam tube to accommodate a cryosorber while eliminating the liner, such as the shape shown in Figure 10. (It looks like a "Mickey Mouse head" if turned around by $90^{\circ}$.) It consists of a beam chamber and two "ears." The beam chamber has a circular cross section with ID $=33 \mathrm{~mm}$, as in the baseline. The "ears" are the antechambers housing the cryosorber material such as coconut charcoal. The chamber and antechambers are connected by a series of pumping slots. This is similar to the beam tubes used in many electron machines except that it preserves the top-bottom symmetry. The symmetry is desirable for reducing the coupling impedance of the slots and the multipole magnetic field errors (e.g., the skew quadrupole component $a_{1}$ ) caused by the non-circular beam tube. The large vertical size of the tube $(47 \mathrm{~mm})$ is compensated by the small horizontal size $(39 \mathrm{~mm})$ so that there is enough room between the tube and the magnet inner coil for the helium flow. 


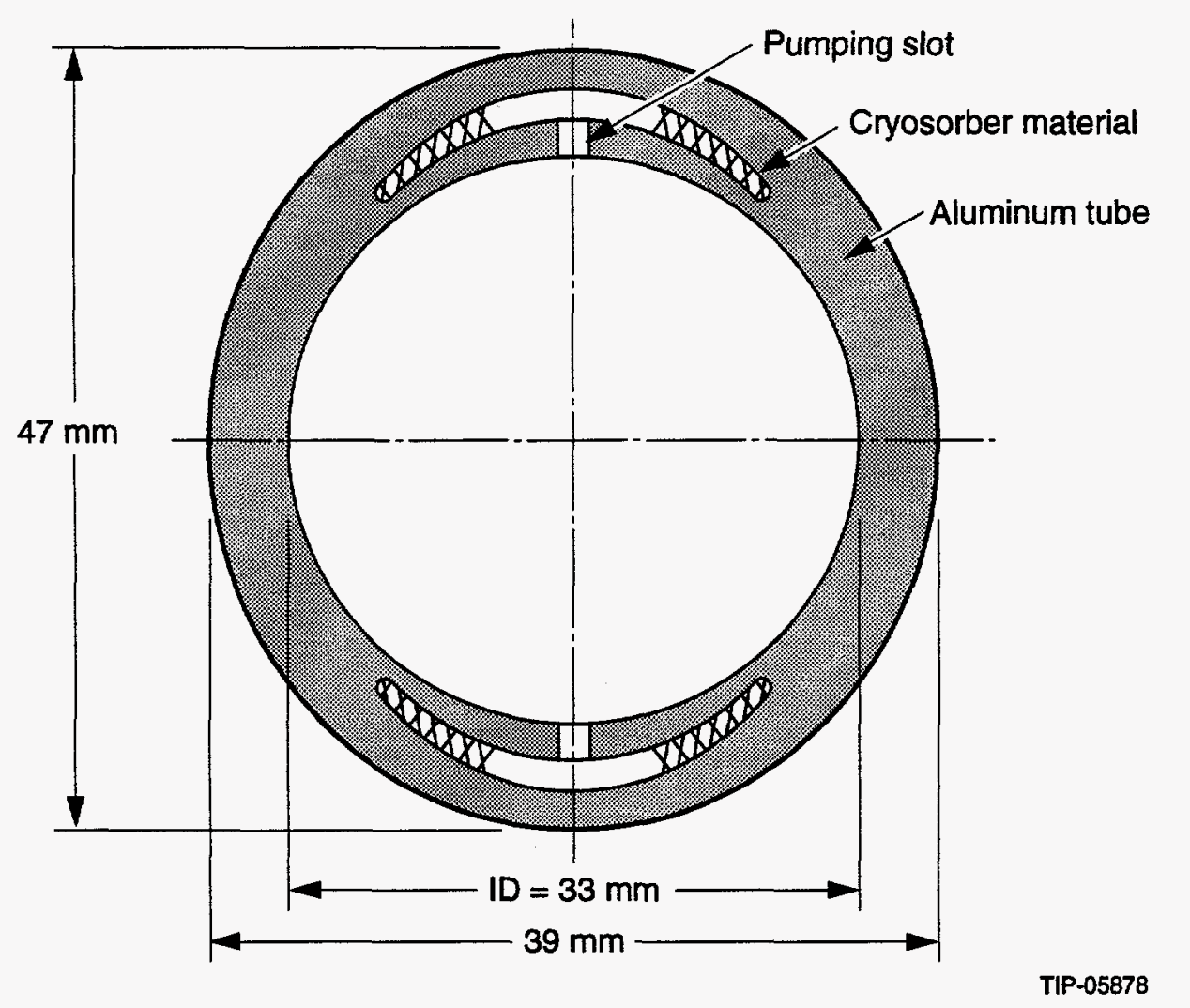

Figure 10. An Aluminum Beam Chamber with Antechamber (the "Mickey Mouse Head" Beam Tube).

One alternative is to rotate the beam tube in Figure 10 by $90^{\circ}$ so that the two "ears" will be located horizontally on left and right instead of on top and bottom. The concerns of such a horizontal configuration are:

- Direct synchrotron radiation in the vicinity of the pumping slots may cause trouble. Recent experience (November 1992) at the HERA electron ring showed that a poor beam lifetime occurred when the synchrotron radiation hit the vicinity of the slots near the distributed ion pump. The mechanism is not clear. One guess was that this was due to ion trapping. (If the guess is correct, then this should not be a problem for the proton beam.)

- The annular space between the tube and the magnet inner coil may be too small $(1.5 \mathrm{~mm})$.

According to the manufacturers, the extrusion of a 60 -foot aluminum tube with such a cross section is feasible. In order to meet the straightness requirement, stretching may be necessary after the extrusion, but it is a straightforward process.

On the other hand, the machining of the slots requires careful study. Although similar work has been done at CERN (the aluminum tube in the LEP is 11.75-m long with 
440 pumping slots), the special difficulty in our case comes from the small size of the beam chamber (ID $=33 \mathrm{~mm}$ ). There are a number of methods that can be investigated, such as milling, hydraulic punching, laser drilling, electrical discharge machining (EDM), or using a movable die during extrusion. A development program will be necessary in order to define a workable and economical way for making the slots.

The main advantage of this implementation is that it can solve the photodesorption problem without using a liner. There are, however, two disadvantages:

- It has to be implemented as the baseline choice of the beam tube. In other words, it cannot be a retrofit.

- It will be difficult to make the beam chamber diameter larger than $33 \mathrm{~mm}$, whereas the magnet measurement technique requires $37 \mathrm{~mm}$.

\subsection{A Beam Chamber with Plate Insertions}

If the limited aperture in the design of the previous section turns out to be prohibitive, then an alternative is to use a circular beam tube with two plate insertions as shown in Figure 11. The beam tube is extruded such that there is small bump on the inner surface that can support the plates. During magnet field measurements, the two plates are not in place and, thus, a larger aperture is available. After the measurements, the two plates, which are perforated and have cryosorber material (e.g., coconut charcoal) on one side, will be inserted into the beam tube for pumping purpose. During quench, the Lorentz force is in the horizontal direction and should not cause any problem to the plates.

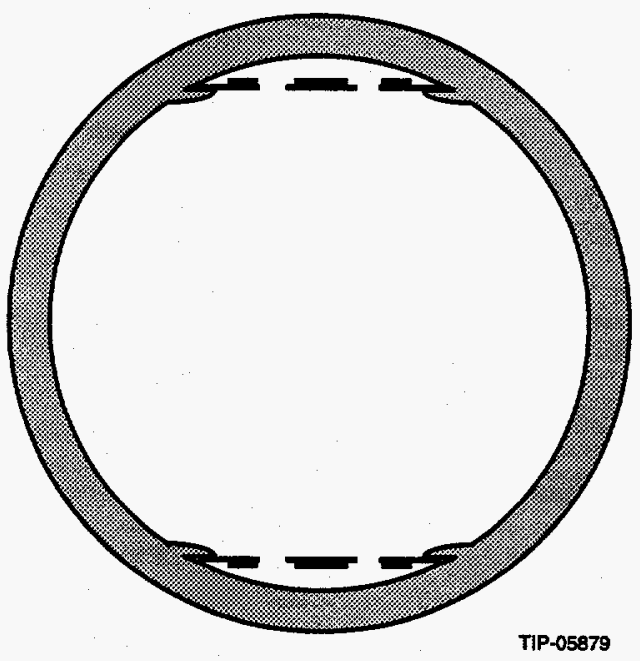

Figure 11. An Aluminum Beam Chamber with Plate Insertions. 


\subsection{A Beam Chamber with an Anodized Layer}

This was originally proposed by W. Nexsen ${ }^{13}$ and is illustrated in Figure 12. The anodized layer serves as a cryosorber. Therefore, no need for a liner. If this idea works, it would probably be the simplest and cheapest way to solve the vacuum problem.

However, there are concerns about the impedance presented by this insulating layer, about the possible saturation when the anodized layer is exposed to the atmosphere, and about the direct exposure of the layer to synchrotron radiation.

If it turns out that the anodized layer does cryopumping but introduces too much impedance, then one may put it in the "Mickey Mouse ears" or on the plate insertions and use it as a cryosorber in place of coconut charcoal.

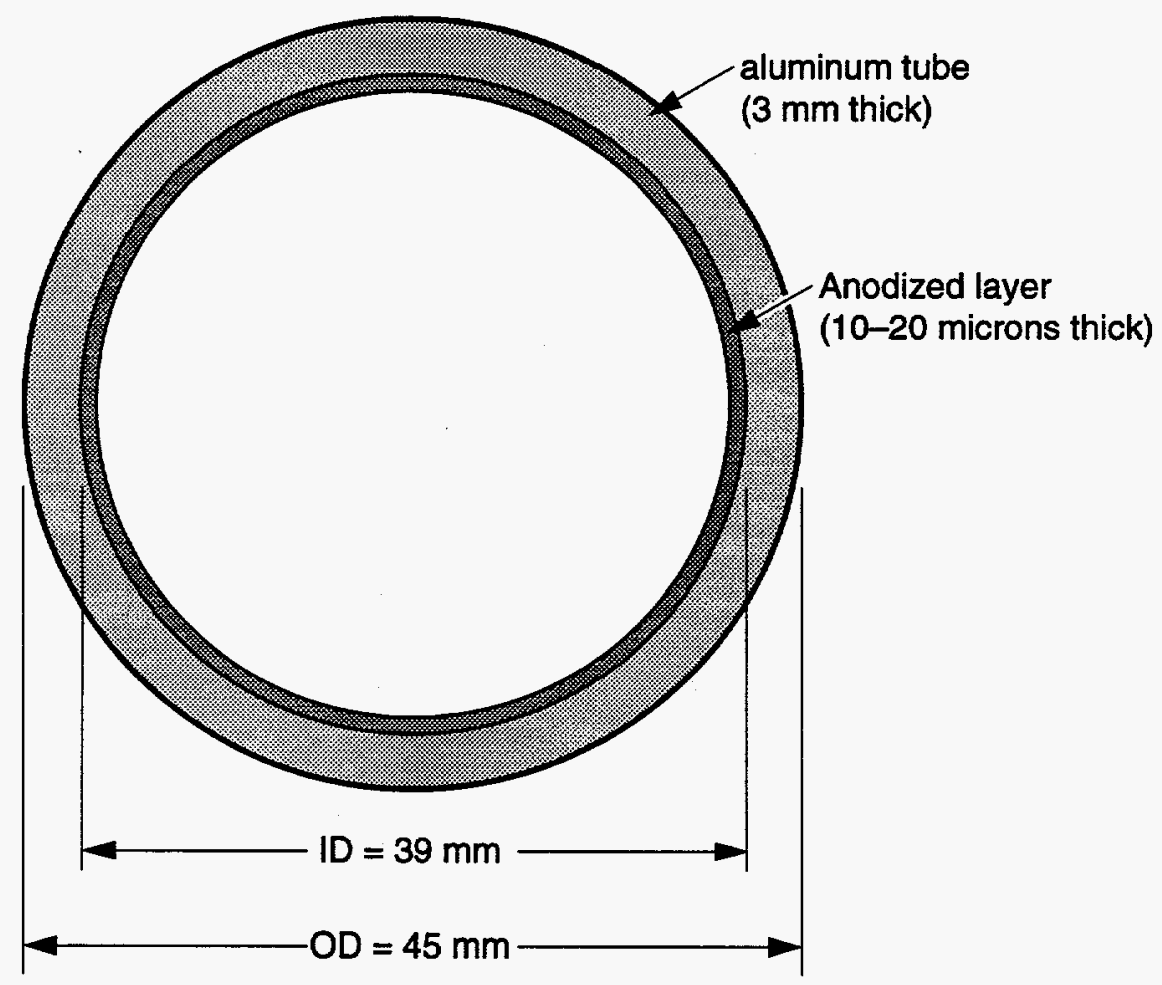

TIP-05880

Figure 12. A Circular Aluminum Alloy Beam Tube with an Anodized Layer.

\subsection{PROPOSED PLAN OF EXPERIMENTAL STUDIES}

We suggest a two-phase plan for experimental studies on the feasibility of the aluminum beam tube.

\subsection{Phase I-Tests of a Circular Aluminum Tube}

The purpose of these tests is to determine if the aluminum tube can replace the coppercoated stainless steel tube in the Collider and if the saving of $\$ 23$ million can be realized. 
The tests are itemized below and possible places to perform the tests are listed in parenthesis.

- Surface resistance measurements at low temperature $(4.5 \mathrm{~K}$ ) for low frequencies (near dc) and high frequencies (1-12 GHz) in a magnetic field varying from 0 to 6.6 Tesla. (LANL)

- Quench test to measure the strain, stress, elastic deflection and plastic deformation. (SSCL, KEK)

- Photodesorption measurements at room temperature (BNL) and LHe temperature (BINP).

- Helium leak test of several types of Al-SST joints - the bolted flange (LANL), the explosion bonded transition piece (SSCL, KEK), and the friction weld (SSCL, DESY).

These tests can be readily incorporated into the Beam Tube Qualification Test Program that has been established by PMO/MSD of this laboratory.

\subsection{Phase II-Tests of an Extruded and an Anodized Aluminum Tube}

If the outcome of Phase $I$ is encouraging, then one can proceed to test the no-liner option.

\subsubsection{Extruded Aluminum Chamber with Antechamber}

- Extrusion of an aluminum tube with a "Mickey Mouse head" cross section, with punched (or milled, or laser drilled) pumping slots. (ALCOA, or IshikawajimaHarima Heavy Industries Co.)

- Simulation and measurement of the error magnetic multipoles due to the non-circular cross section of the aluminum tube. (SSCL)

- Simulation and measurement of the quench-induced stress distribution. (SSCL)

- Installation of the cryosorber in the antechamber (CEBAF); warm and cold measurements of photodesorption (BNL, BINP).

\subsubsection{Extruded Aluminum Chamber with Plate Insertions}

- Extrusion of an aluminum tube with small bump on its inner surface; perforation of aluminum plates. (ALCOA, or Ishikawajima-Harima Heavy Industries Co.)

- Simulation and measurement of the error magnetic multipoles due to the plate insertions. (SSCL)

- Simulation and measurement of the quench induced stress distribution. (SSCL)

- Attachment of the cryosorber material onto one side of the plates, insertion of the plates into the beam chamber (CEBAF); warm and cold measurements of photodesorption (BNL, BINP). 


\subsubsection{Anodized Aluminum Tube}

- Treatment of an aluminum tube to form a thin $(\sim 10-20 \mu)$ anodized layer on the inner surface. (LANL or ALCOA)

- Surface resistance measurements. (LANL)

- Warm and cold photodesorption measurements (BNL, BINP). 


\section{ACKNOWLEDGEMENTS}

The author would like to thank H. Ishimaru, R. Shutt, G.Q. Lu, F. Koide, K. Leung, W. Nexsen, Q. Shu, W. Turner, D. Clark, R. Thiagarajan and many others for interesting and stimulating discussions, and T. Barts for helping with preparing the figures. 


\section{REFERENCES}

1. Y. Suetsugu and H. Ishimaru, Japanese Journal of Appl. Phys., Vol. 27, p. 1077 (June 1988).

2. J.T. Rogers et al., Appl. Phys. Lett., Vol. 52, p. 2266 (June 1988).

3. E. Gray, LANL, private communication.

4. K.-Y. Ng and J. Peterson, SSC-168 (March 1988).

5. R.P. Shutt, ISABELLE Division Technical Note No. 52, BNL (August 31, 1977). The equations here are modification of that in Shutt's paper due to different unit system in use.

6. K. Leung, SSCL, private communication.

7. K. Leung, SSCL, private communication.

8. H. Ishimaru and M. Nilno, Result of Quench Test for Aluminum Alloy Clad Pipe, unpublished.

9. A.G. Mathewson et al., American Vacuum Society Series 12, Conference Proceedings No. 236, Vacuum Design of Synchrotron Light Sources, p. 323 (1991).

10. W. Chou, Bunch Induced Multipactoring at the SSC, SSC Laboratory Internal Technical Note PMTN-0081C (November 1993).

11. N.G. Wilson, C. Bridgeman and R.J. Grieggs, Conference Record of the 1991 IEEE Particle Accelerator Conference, Vol. 4, pp. 2459-2461.

12. H. Kaiser, DESY, private communication.

13. W. Nexsen, memo to W. Turner, SSCL, Sept. 27, 1991. 